\title{
The magnetic resonance neurography of a Parsonage-Turner syndrome case
}

\author{
(D) Selcuk Sayilir, ${ }^{1}$ (D) Nesat Cullu, ${ }^{2}$ (D) Timur Ekiz ${ }^{3}$ \\ ${ }^{1}$ Department of Physical Medicine and Rehabilitation, Mugla Sitki Kocman University Faculty of Medicine, Mugla, Turkey \\ ${ }^{2}$ Department of Radiology, Mugla Sitki Kocman University Faculty of Medicine, Mugla, Turkey \\ ${ }^{3}$ Department of Physical Medicine and Rehabilitation, Dermancan Medical Center, Adana, Turkey
}

Cite this article as: Sayilir S, Cullu N, Ekiz T. The magnetic resonance neurography of a Parsonage-Turner syndrome case. North Clin Istanb 2020;7(1):65-66.

A 42-year-old woman was seen due to severe pain and weakness in her shoulders bilaterally for ten days. She stated that her symptoms had started suddenly after two consecutive (between few hours) generalized tonic clonic seizures. The pain was present at rest and worse with movement since the second seizure onset. Medical history as regards any fever, diarrhea, and infection were noncontributory.

Physical examination revealed restriction in shoulder movements, weakness of the supra/infraspinatus, deltoid, biceps and brachioradialis muscles bilaterally, and normal sensorial findings. Laboratory findings were within normal limits except increased levels of creatine kinase (7300 U/1, normal: 0-170) at the third day of the symptoms onset. Microbial and biochemistral investigations of the cerebrospinal fluid and cranial magnetic resonance imaging (MRI) were normal. Electroencephalography was normal. Cervical (C) MRI findings were insignificant. Electroneuromiyographic examination showed acute denervation of the axillary and musculocutaneous nerves on the left and axillary nerve on the right upper extremity. Ten days after the first visit (20 days after the symptom onset), shoulder pain and weakness were remained, creatine kinase level decreased to $67 \mathrm{U} / 1$. Regarding the EMG examination outcomes, a brachial plexus magnetic resonance neurography was performed and it showed thickening and high signal in-

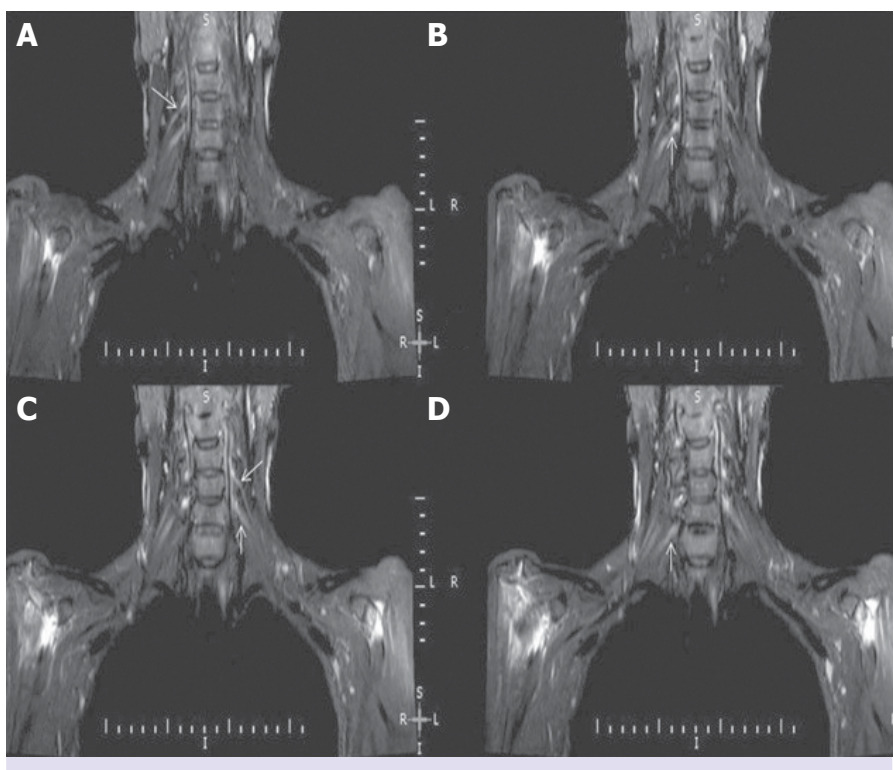

FIGURE 1. Magnetic resonance neurography. Magnetic resonance neurography shows thickening and high signal intensity from the postganglionic $\mathrm{C} 5-\mathrm{C} 6-\mathrm{C} 7$ at the right (A, B, D) and $\mathrm{C5}-\mathrm{C6}$ at the left (C) in coronal STIR images.

tensity from the postganglionic $\mathrm{C} 5-\mathrm{C} 6-\mathrm{C} 7$ at the right and C5-C6 at the left in coronal STIR images (Fig. 1). Overall, the patient was diagnosed with neuralgic amyotrophy (NA) and metilprednizolon $120 \mathrm{mg}$ (only one intramuscular dose after 15 days the symptom onset), levetiracetam $1000 \mathrm{mg} /$ day and pregabalin $150 \mathrm{mg} /$ day

Received: July 02, 2018 Accepted: April 15, 2019 Online: 25 June, 2019

Correspondence: Dr. Selcuk SAYILIR. Mugla Sitki Kocman Universitesi Tip Fakultesi, Fiziksel Tip ve Rehabilitasyon Anabilim Dali, Mugla, Turkey.

Tel: +902522141326 e-mail: selcukssay@gmail.com

(c) Copyright 2020 by Istanbul Provincial Directorate of Health - Available online at www.northclinist.com 
were administered for her symptoms and seizure history by the Department of Neurology. Additionally, a rehabilitation program, including range of motion, and isometric strengthening exercises were started. One month later, her pain relieved (visual analog scale decreased from 9 to 6) and a mild improvement was detected for weakness. Informed consent was obtained from the patient. Neuralgic amyotrophy, also known as the Parsonage-Turner syndrome, is characterized with acute and severe pain/paresis particularly in the upper extremities and seen with an incidence of 2-3/100000 per year. By and large, the upper and middle trunks of the brachial plexus are affected. NA can be sporadic or seen in an autosomal dominant manner. The etiopathology is not clearly understood. However, peripheral nerve biopsies of NA yielded inflammatory and autoimmune responses, perineural thickening, epineural perivascular mononuclear T-cell infiltration, active multifocal axonal degeneration, but not vessel wall inflammation or necrosis. In this study, we are presenting our case with MRI evaluations. We should note that early rehabilitation program for this syndrome may have benefits for preventing immobilization-related problems, as well as improving affected muscle strength and relieving pain. 